\title{
Community Mental Health Journal Welcomes New Lead Editors
}

\author{
Sandra Steingard ${ }^{1}$
}

Accepted: 28 January 2021 / Published online: 9 February 2021

(C) The Author(s), under exclusive licence to Springer Science+Business Media, LLC part of Springer Nature 2021

As I work to advance the mission of the Journal and continue to learn about my role as Editor-in-Chief, I have restructured the leadership team to assist me in achieving our goals. In January 2021, we introduced the positions of Lead Editors. They will help identify important areas of scholarship and guide me in the review process. In the upcoming months we will continue to improve our work on antiracism and the inclusion of members of those groups that have been underrepresented in academic publishing. I am pleased that Drs. Jessica Isom, Nev Jones, Rebecca Miller, and Sarah Vinson have joined our leadership team.

Isom is a board-certified community psychiatrist and clinical instructor at the Yale School of Medicine Department of Psychiatry. She is an attending psychiatrist at Codman Square Health Center as well as Boston Medical Center. She holds a number of leadership positions in psychiatric organizations. Her professional activities entail efforts at reducing racial and ethnic mental health disparities, mitigating the impact of implicit racial bias on clinical care, and the use of a community-focused population health approach in psychiatric practice. Her anti-racism teaching highlights the history of medical racism and interpersonal challenges in interracial interactions and provides a language for naming and responding to racism at multiple levels.

Jones is an assistant professor in the Department of Psychiatry at the Morsani College of Medicine at the University of South Florida. A community psychologist and mental health services researcher, her work focuses on understanding the social and structural determinants of disability and recovery among individuals with significant psychiatric impairments, with a particular focus on psychosis and user-driven innovation and quality improvement. She is a nationally recognized expert in stakeholder involvement in research and is known for her advocacy of a fundamental

Sandra Steingard

sandysteingard@gmail.com

1 University of Vermont Larner College of Medicine, Burlington, USA rethinking of public sector mental health systems and services.

Miller is a licensed clinical psychologist and associate professor in the Department of Psychiatry at the Yale School of Medicine. Her research work at the Yale Program for Recovery and Community Health has focused on training and research in person-centered approaches to care, peer support, and citizenship for people with mental illness. Other interests include education and training of psychologists and psychiatry residents, systems transformation, innovative approaches to working with people with serious mental illness and recovery-oriented care. She currently serves as Director of Peer Support and Family Initiatives at CMHC, where she uses her own lived experience with mental illness to inform her work.

Vinson is a triple-board-certified child \& adolescent, adult, and forensic psychiatrist. She is an associate clinical professor in the Departments of Psychiatry and Pediatrics at Morehouse School of Medicine, where she was the lead architect and is the program director for the Child Psychiatry Fellowship, the first and only at an HBCU medical school. She is also a member of the adjunct faculty at Emory School of Medicine. Dr. Vinson is the co-editor of two texts: Social (In)Justice and Mental Health and Pediatric Mental Health for Primary Care Providers. She has written book chapters and/or peer-reviewed articles on the social determinants of children's mental health, childhood trauma, social media and children's mental health, fostering resilience, the criminalization of mental illness, and the school-to-prison pipeline. Dr. Vinson has been elected and/or appointed to national and statewide offices by her professional peers. She serves on the boards of the American Association of Community Psychiatry and of the Bazelon Center for Mental Health Law.

I also extend my gratitude and appreciation to Drs. Curtis Adams and Margaret Balfour who are transitioning from their roles as Associate Editors to the Editorial Board. Drs. Adams and Balfour, both leaders in community psychiatry and with the American Association for Community Psychiatry, served for many years as Associate Editors. They were instrumental in supporting me through the transition and I 
am pleased that they will continue to support the journal by serving on our Editorial Board.
Publisher's Note Springer Nature remains neutral with regard to jurisdictional claims in published maps and institutional affiliations. 